\title{
Effectiveness of a heel cup with an arch support insole on the standing balance of the elderly
}

This article was published in the following Dove Press journal:

Clinical Interventions in Aging

20 February 2014

Number of times this article has been viewed

\author{
Tzu-Hsuan Chen ${ }^{1, *}$ \\ Li-Wei Chou ${ }^{2,3, *}$ \\ Mei-Wun Tsai ${ }^{4}$ \\ Ming-Jor Lo ${ }^{5}$ \\ Mu-Jung Kao $\mathrm{Ka}^{4}$
}

'Department of Rehabilitation, Mackay Memorial Hospital, Hsinchu, Taiwan; ${ }^{2}$ Department of Physical Medicine and Rehabilitation, China Medical University Hospital, Taichung, Taiwan; ${ }^{3}$ School of Chinese Medicine College of Chinese Medicine, China Medical University, Taichung, Taiwan; ${ }^{4}$ Department of Physical Therapy and Assistive Technology, National Yang-Ming University, Taipei, Taiwan; ${ }^{5}$ Department of Rehabilitation, Yangming Branch, Taipei City Hospital, Taipei, Taiwan

*These authors contributed equally to this paper
Correspondence: Mu-Jung Kao Department of Rehabilitation, Taipei City Hospital, Yangming Branch, No 105, Yu Sheng Road, Shilin District, Taipei II I, Taiwan

Tel +886228353456 ext 6606

Fax +886 22837812 I

Emailwoodkao35@yahoo.com.tw
Background: The use of insoles may enhance postural stability and prevent falls. The aim of this study was to design a new insole and to explore the effectiveness of the insole on the standing balance of the healthy elderly.

Methods: The study was conducted at a community hospital. Patients older than 65 years at an outpatient clinic without abnormal gait patterns, lower limb deformities, or foot pain were enrolled. The participants were assigned to good- and poor-stability groups on the basis of the stability index (SI), using the Biodex ${ }^{\circledR}$ Balance System. A heel cup with an arch support insole was provided. Participants wore the insole for 8 weeks for a minimum of 4 hours/day. A static balance test for SI was performed at the initial meeting and 8 weeks after the assigned insoles were worn for each participant.

Results: Five participants (10.0\%) of 50 total did not finish the study. There were 25 patients in the good-stability group and 20 in the poor-stability group. The SI, before and after intervention, was significantly different for all 45 participants (3.244 \pm 0.688 versus $3.064 \pm 0.671$; $P<0.001)$. The differences in SI before and after the intervention both in the good-stability group $(2.764 \pm 0.546$ versus $2.592 \pm 0.538)$ and the poor-stability group $(3.845 \pm 0.188$ versus $3.655 \pm 0.128)$ were statistically significant $(P<0.001)$. No statistically significant difference on changes of SI were seen between the two groups.

Conclusion: The results suggest a heel cup with arch support insole is effective in enhancing the standing balance of the elderly. This may be of benefit in preventing falls.

Keywords: insole, heel cup, stability, standing balance, elderly

\section{Introduction}

The foot is the first contact between the body and the external environment while standing, providing sensory information to the central nervous system for stability and locomotion. Tactile sensitivity within the foot has a strong influence on maintenance of postural stability. ${ }^{1,2}$ The maintenance of postural stability is dependent on a range of somatosensory inputs, and postural stability and balance are dependent on the position of the center of mass of the body and its displacement within the base of support. ${ }^{3}$ However, in adults aged 65 years or older, diminished somatosensation is associated with an increased likelihood of falling. ${ }^{4}$ As we know, the link between postural stability and falls is well documented, with postural instability deficits being significant predictors of falls in older adults. ${ }^{5,6}$ As the older population is growing, there is an increasing need to ensure that appropriate footwear will reduce the risk of falls, enhance cushioning, and decrease pain and impairment. Footwear may influence the quality of sensory feedback from the feet and may act as a sensory filter between 
the feet and the external environment. ${ }^{7-9}$ Therefore, in our study, we tried to design a new insole to improve the standing balance of the elderly.

We reviewed current literature for design and material choices for insoles. The literature demonstrates that shoe inserts and foot orthotics (FO) are thought to affect sensory feedback from the feet and aid postural control. ${ }^{10}$ Previous studies investigating stimulation of the soles of the feet through textured FO, ${ }^{9,11}$ magnetic $\mathrm{FO},{ }^{12}$ and vibrating $\mathrm{FO}^{13}$ are associated with improvements in balance control and reduce postural sway. Shoe inserts and FO are thought to affect sensory feedback from the feet and aid postural control. ${ }^{10}$

The muscle function and strength of older people are both relatively unstable and weak. Foot insoles are widely used to treat flat feet or arch pain and provide pain relief. However, it has been suggested that soft materials negatively affect stability during locomotion, and for optimal stability, shoes with thin, hard FO are preferable. ${ }^{14,15}$ This is why we did not choose traditional total-contact insoles or a soft material but designed a heel cup with an arch support insole for the elderly.

Studies related to the treatment of foot disease or the distribution of foot pressure using foot orthoses or insoles have been performed before; however, few studies have reported on the function of the insole in the standing balance of elder people to prevent falling. The purpose of the current study is to determine whether a heel cup with an arch support insole can improve balance control during standing after 8 weeks of wearing the insole daily.

\section{Methods}

\section{Subjects}

The study was conducted at a community hospital by wellexperienced therapists and physiatrists. Fifty men and women were recruited from the outpatient clinic of a community hospital from January 2011 to June 2011. All subjects were older than 65 years and were able to follow instructions. An experienced physiatrist examined all of them. Subjects were excluded if they had evidence of abnormal gait patterns (such as festinating gait, steppage gait, spastic gait, scissoring gait, waddling gait, circumduction gait, antalgic gait, and stiff-knee gait), lower limb deformities, or foot pain. Their history of falls was recorded. The study was approved by the Institutional Review Board of Taipei City Hospital, and informed consent was obtained from all subjects before their participation.

\section{Procedure}

Patients were instructed to stand in the middle of a platform of the Biodex ${ }^{\circledR}$ Balance System (Biodex, Shirley, NY, USA), using mechanical coils to evaluate the stability index (SI), with their feet separated shoulder-width apart and their eyes open. They were wearing their own shoes. The Biodex ${ }^{\circledR}$ Balance System uses a circular platform that is free to move about the anterior-posterior and medial-lateral axes simultaneously. These devices have typically used force plates combined with computer software to determine the movement of the center of pressure (COP). The COP is the central point of pressure that is applied to the foot during contact with the ground or the point of application of the ground reaction force on the foot. During stance, the COP can be used to measure the movement of the individual's center of gravity over the foot. Thus, the COP can be used to index the amount of movement or sway of the center of gravity during stance. The Biodex ${ }^{\circledR}$ Balance System has 12 levels of stability test. The SI scores were taken from static balance tests with three cycles at level 8 over a period of 20 seconds. ${ }^{16}$ According to the standard range of SI for different age groups, all participants underwent a static balance test with the same customized shoes and were assigned into the good- and poor-stability groups according to the acquired SI after a static balance test compared with the standard range of SI for different age groups, such as age 54-71 years with an SI range of 1.79-3.35, and age 72-89 with an SI range of 1.90-3.50. A lower SI represents better stability (Table 1).

Subjects were assigned to use a heel cup with arch support insoles. The heel cup was made of a high-density polyurethane (PU) customized insole with three sizes (small, middle, and large) (Figure 1). Subjects received metatarsal pads, and long arch support was provided. The subjects were required to wear the insoles for 8 weeks for a minimum period of 4 hours/day. The compliance of wearing the insole was good, according to self-report by subjects.

A static balance test was performed as outcome measurement for all subjects during the initial screening and after 8 weeks of the test. In the current study, a Biodex ${ }^{\circledR}$ Balance System that controls the stability of a platform, using mechanical coils, was used to evaluate SI. The sway angle of the foot can be easily measured, and a simple and

Table I The standard range of stability index for different age groups

\begin{tabular}{ll}
\hline Age, years & Stability index (range) \\
\hline $17-35$ & $0.82-2.26$ \\
$36-53$ & $1.23-3.03$ \\
$54-71$ & $1.79-3.35$ \\
$72-89$ & $1.90-3.50$ \\
\hline
\end{tabular}

Note: On the basis of age, the subject is classified into the poor-stability group if the score of the stability index is greater than the range. 


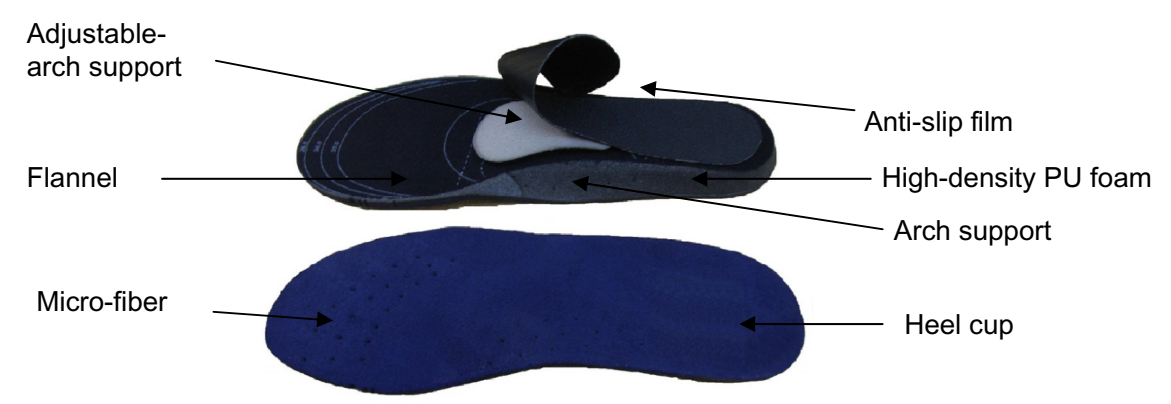

Figure I The heel cup was made up of a high-density polyurethane (PU) customized insole with an arch support insole for the participants. The adjustable sandwich insole is constructed with super-thin Velcro. It is a single modualized custom-made insole with adjustable inserts. The microfiber or natural leather layer is wear-resistant and moisture wicking, which keeps feet dry and comfortable. The high-density breathable PU layer is designed for long-term use without deformation and protects the foot by dampening shocks.

reliable balance index can be easily obtained; thus, the system was suitable for large sampling measurements and balance evaluation in specific people.

The participants stood in the middle of the platform, feet separated at shoulder width, and underwent three cycles of the level 8 stability tests for a total of 20 seconds. Ten seconds of rest were given between each test. The average values were then obtained from three times of repeated testing. The change in SI at the baseline and 8 weeks after intervention was evaluated.

\section{Intervention}

Soft materials negatively affect stability during locomotion, and for optimal stability, shoes with thin, hard FO are preferable. ${ }^{14,15}$ Thus, our heel cup was made of a high-density PU customized insole with three sizes. In addition, the muscle function and strength of older people are relatively unstable and weak. Therefore, the arch support design and tablemat appearance were applied to increase the total contact area of the foot and stabilize the ankle. A special bubbled layer is most suitable for sweaty people. The advantages of this product are as follows: a) comfortable: it has a superfine fiber or a natural leather surface that is tolerant to rubbing or can absorb moisture to keep the foot dry and comfortable; b) breathable: it is made of a high-density, breathable, absorptive PU material bubble layer that can be used for a long time without deforming; c) cushion: the impact of the body is reduced via impact absorption of the high-density PU layer; and d) reaction force: it has an extremely good reaction force of the forefoot to propel the body during vigorous exercise (Figure 1).

\section{Data analysis}

Baseline descriptive information was obtained from each subject and analyzed. All data were performed using Statistical Package for Social Science (SPSS, version 14.0;
IBM Corporation, Armonk, NY, USA). The paired $t$-test was used to compare the differences before and after intervention to determine the effect of the heel cup with arch support insoles on the standing balance of the elderly. Two-way analysis of variance was used to compare the good- and poorstability groups among before and after intervention groups. A $P<0.05$ value was considered statistically significant.

\section{Results}

All 50 participants were initially screened using a static balance test; 30 were placed in the good-stability group, whereas 20 were put in the poor-stability group. Five participants did not finish the study because of personal reasons. The remaining 45 subjects $(90.0 \%$; age $=71.29 \pm 6.12$ years, mean \pm standard deviation [SD]) included 25 in the good-stability group (age $=73.56 \pm 5.90$ years, mean $\pm \mathrm{SD}$ ) and 20 in the poorstability group (age $=69.35 \pm 4.96$ years, mean $\pm \mathrm{SD})$. The ages were significantly different between the two groups $(P<0.05)$. The SI, before and after intervention, was significantly different for the 45 participants (3.244 \pm 0.688 versus $3.064 \pm 0.671$, mean $\pm \mathrm{SD} ; P<0.001)$. The differences of SI between before and after intervention both in the good-stability group $(2.764 \pm 0.546$ versus $2.592 \pm 0.538$, mean \pm SD) and the poorstability group $(3.845 \pm 0.188$ versus $3.655 \pm 0.128$, mean \pm SD) were statistically significant $(P<0.001$; Table 2$)$. No statistically significant difference was seen on change of SI between the two groups (Figure 2).

\section{Discussion}

Fall prevention is an important part of health care of the elderly. The aim of the study was to evaluate the foot insole, especially the newly invented heel cup with arch support insole, in relation to standing balance in asymptomatic elder adults. Because standing stability is an important component of balance in the elderly, in adults aged 65 years or older, 
Table 2 Stability index comparison before and after intervention

\begin{tabular}{lll}
\hline & $\begin{array}{l}\text { Before } \\
\text { intervention } \\
\text { Mean } \pm \text { standard } \\
\text { deviation }\end{array}$ & $\begin{array}{l}\text { After } 8 \text { weeks } \\
\text { of intervention } \\
\text { Mean } \pm \text { standard } \\
\text { deviation }\end{array}$ \\
\hline Total $(\mathrm{N}=45)^{*}$ & $3.244 \pm 0.688$ & $3.064 \pm 0.67 \mathrm{I}$ \\
Good-stability & $2.764 \pm 0.546$ & $2.592 \pm 0.538$ \\
group $(\mathrm{N}=25)^{* *}$ & $3.845 \pm 0.188$ & $3.655 \pm 0.128$ \\
Poor-stability & & \\
group $(\mathrm{N}=20)^{* *}$ & &
\end{tabular}

Notes: $P<0.05$ is statistically significant. *Paired $t$-test showed a statistically significant $(P<0.001)$. **Comparison between good and poor groups by two-way analysis of variance. Main effect: I) class effect, $P<0.00 I$; 2) time effect, $P<0.00$ I; and 3) interaction effect, $P=0.671$.

diminished somatosensation is associated with an increased likelihood of falling. ${ }^{4}$ Tests of standing balance are frequently included in neurological evaluations, but few objective data are available to indicate how well aged individuals are able to maintain a standing balance. Reports on improving the standing stability of the elderly, using foot orthoses, are also scarce. As we know, the loss of cutaneous sensation in the plantar surface (sole) of the feet has been correlated with impaired balance control and increased risk of falling. ${ }^{17,18}$ In a previous study, Bohannon et al reported that subjects over 60 years of age are unable to balance on one leg, particularly when their eyes are closed, for a period as long as that maintained by younger subjects. ${ }^{19}$ However, the effect of foot orthoses on standing stability has received limited attention, although foot insoles may be prescribed for a range of lower limb and foot conditions. In the present study, the performance of a newly designed heel cup with an arch support insole in improving the standing balance control of the elderly (those older than 65 years) was investigated.

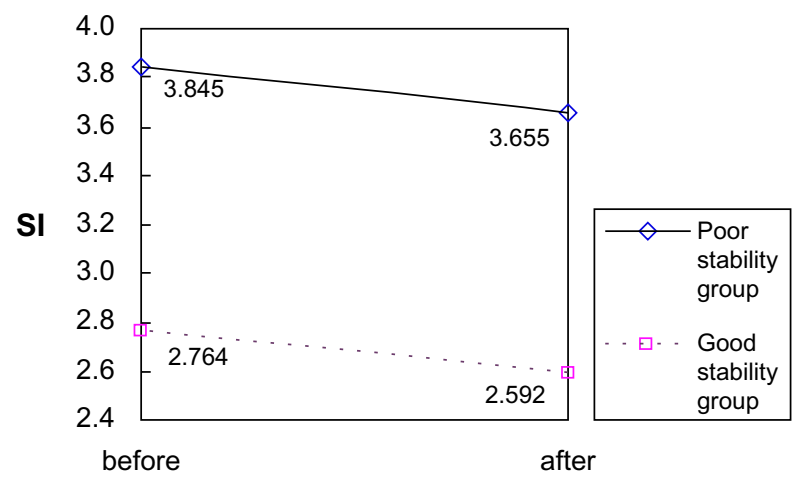

Figure 2 The heel cup with arch support insoles had an effect on the stability index (SI) of either group and had no statistically significant difference on changes of stability index between two groups, indicating that the heel cup with arch support insoles improved the standing stability of the healthy elderly both in good- and poorstability groups.
Evidence suggests that lower extremity injuries, particularly lateral ankle sprain, lead to impaired lower-extremity proprioception and measurable defects in postural stability. ${ }^{20-25}$ That is why only individuals who met the exclusion criteria without the musculoskeletal system, nerve system, or foot-associated disease were allowed to participate in the study.

In a previous study, Guskiewicz and Perrin reported that custom-made foot orthoses improved the balance performance of subjects with recent ankle sprains in response to platform perturbation but had no effect on uninjured subjects. ${ }^{26}$ In a similar investigation, Orteza et al evaluated the performance on a balance board of subjects with and without a recent ankle sprain wearing either semirigid molded orthoses or soft, unmolded orthoses. ${ }^{27}$ The semirigid molded orthoses produced a significant improvement in the balance performance of the injured subjects but had no effect on the uninjured subjects. The soft, unmolded orthoses had no effect on the balance of either group. Contrary to these findings, Stude and Brink reported that flexible molded foot orthoses improved balance in injury-free experienced golfers both before and after the activity and suggested that the benefits of foot orthoses may not be restricted to people with ankle instabilities. ${ }^{28}$ However, in the current study, because our study design was for healthy patients, we did not focus on the effect of the use of foot orthoses in relation to ankle sprain and instability.

However, in our study, the improvement of SI showed significant beneficial effects on either group and no statistically significant difference on changes of SI between two groups, indicating that the heel cup with arch support insoles improved the standing stability of the healthy elderly both in the good- and poor-stability groups (Figure 2). In this way, it could prevent falling accidents. Two mechanisms have been proposed to illustrate the apparently beneficial effects of the ankle support and foot orthoses on standing stability. First, external bracing has been found to significantly restrict foot and ankle movements, which may improve mechanical stability. ${ }^{29,30}$ Second, these devices may affect the proprioceptive awareness of the limb position by stimulating the cutaneous mechanoreceptors when in contact with the skin. ${ }^{25,31}$ However, evidence also suggests that placing compliant materials under the foot reduces proprioceptive awareness ${ }^{31,32}$ and impairs postural stability. ${ }^{33-35}$ These findings may also explain the result obtained from the current study.

It has been suggested that soft materials negatively affect stability during locomotion, and for optimal stability, 
shoes with thin, hard FO are preferable. ${ }^{14,15}$ The relationship between material compression and balance was recently explored by Robbins et al, ${ }^{36}$ who found that the shoe material has little effect on the sway if it remains compressed between steps, whereas it may impair the stability if it recoils. When the material used in the insoles was fairly thin and compressible, the body weight maximally compressed the insole for the duration of trial when the subject was standing. The footwear was described as being quite tight when the soft insoles were worn, suggesting that the insoles may have been in a continuously compressed state.

Therefore, in the present study, the high-density PU material was used for the contact surface of the feet. In addition, the heel cup with an arch support insole increased the contact surface of the foot and improved the ankle, standing, and ambulation stabilities. Only some of the participants felt that the arch support was insufficient; thus, adjustable pads that fit different morphologic foot types can be developed in the future. Compliance was good. Hence, most of the subjects considered the contact surface of the foot made by the highdensity PU material as flexible, capable of prolonging both standing and ambulation duration. In our study, the highdensity PU material was found to have beneficial effects on the standing control of elderly individuals and is thus suitable for use in insoles.

\section{Conclusion}

The current study demonstrated that a heel cup with an arch support insole significantly improved SI and increased standing balance. Prospective studies will be required to determine whether this effect reduces the incidence of falls in elderly individuals.

\section{Acknowledgments}

This study was supported by grants (99001-62-023) from the Department of Health, Taipei City Government, Republic of China.

\section{Author contributions}

All authors participated in critical revision and approved the final manuscript. THC, MJK, MJL, and LWC conceived the study and supervised its design, execution, and analysis and participated in the drafting and critical review of the manuscript. MWT and MJK did data management and statistical analyses. THC and LWC wrote the paper with input from all investigators.

\section{Disclosure}

The authors report no conflicts of interest in this work.

\section{References}

1. Simoneau GG, Ulbrecht JS, Derr JA, Cavanagh PR. Role of the somatosensory input in the control of human posture. Gait Posture. 1995;3(3):115-122.

2. Gutierrez EM, Helber MD, Dealva D, Ashton-Miller JA, Richardson JK. Mild diabetic neuropathy affects ankle motor function. Clin Biomech (Bristol, Avon). 2001;16(6):522-528.

3. Gatev P, Thomas S, Kepple T, Hallett M. Feedforward ankle strategy of balance during quiet stance in adults. $J$ Physiol. 1999;514(Pt 3): 915-928.

4. Judge JO, King MB, Whipple R, Clive J, Wolfson LI. Dynamic balance in older persons: effects of reduced visual and proprioceptive input. J Gerontol A Biol Sci Med Sci. 1995;50(5):M263-M270.

5. Rubenstein LZ, Josephson KR. The epidemiology of falls and syncope. Clin Geriatr Med. 2002;18(2):141-158.

6. Stalenhoef PA, Diederiks JP, Knottnerus JA, Kester AD, Crebolder HF. A risk model for the prediction of recurrent falls in community-dwelling elderly: a prospective cohort study. J Clin Epidemiol. 2002;55(11): 1088-1094.

7. Arnadottir SA, Mercer VS. Effects of footwear on measurements of balance and gait in women between the ages of 65 and 93 years. Phys Ther. 2000;80(1):17-27.

8. Mündermann A, Stefanyshyn DJ, Nigg BM. Relationship between footwear comfort of shoe inserts and anthropometric and sensory factors. Med Sci Sports Exerc. 2001;33(11):1939-1945.

9. Waddington G, Adams R. Textured insole effects on ankle movement discrimination while wearing athletic shoes. Phys Ther Sport. 2000;1(4):119-128.

10. Nigg BM, Nurse MA, Stefanyshyn DJ. Shoe inserts and orthotics for sport and physical activities. Med Sci Sports Exerc. 1999;31(Suppl 7): S421-S428.

11. Nurse MA, Hulliger M, Wakeling JM, Nigg BM, Stefanyshyn DJ. Changing the texture of footwear can alter gait patterns. J Electromyogr Kinesiol. 2005;15(5):496-506.

12. Suomi R, Koceja DM. Effect of magnetic insoles on postural sway measures in men and women during a static balance test. Percept Mot Skills. 2001;92(2):469-476.

13. Priplata AA, Niemi JB, Harry JD, Lipsitz LA, Collins JJ. Vibrating insoles and balance control in elderly people. Lancet. 2003;362(9390): $1123-1124$.

14. Robbins S, Waked E. Balance and vertical impact in sports: role of shoe sole materials. Arch Phys Med Rehabil. 1997;78(5):463-467.

15. Rome K, Brown CL. Randomized clinical trial into the impact of rigid foot orthoses on balance parameters in excessively pronated feet. Clin Rehabil. 2004;18(6):624-630.

16. Schmitz R, Arnold B. Intertester and intratester reliability of a dynamic balance protocol using the Biodex Stability System. J Sport Rehabil. 1998;7:95-101.

17. Lord SR, Menz HB, Tiedemann A. A physiological profile approach to falls risk assessment and prevention. Phys Ther. 2003;83(3):237-252.

18. Lord SR, Ward JA, Williams P, Anstey KJ. Physiological factors associated with falls in older community-dwelling women. JAm Geriatr Soc. 1994;42(10):1110-1117.

19. Bohannon RW, Larkin PA, Cook AC, Gear J, Singer J. Decrease in timed balance test scores with aging. Phys Ther. 1984;64(7):1067-1070.

20. Freeman MA, Dean MR, Hanham IW. The etiology and prevention of functional instability of the foot. J Bone Joint Surg Br. 1965;47(4): 678-685.

21. Glencross D, Thornton E. Position sense following joint injury. J Sports Med Phys Fitness. 1981;21(1):23-27. 
22. Garn SN, Newton RA. Kinesthetic awareness in subjects with multiple ankle sprains. Phys Ther. 1988;68(11):1667-1671.

23. Tropp H, Ekstrand J, Gillquist J. Stabilometry in functional instability of the ankle and its value in predicting injury. Med Sci Sports Exerc. 1984;16(1):64-66.

24. Fridén T, Zätterström R, Lindstrand A, Moritz U. A stabilometric technique for evaluation of lower limb instabilities. Am J Sports Med. 1989;17(1):118-122.

25. Feuerbach JW, Grabiner MD, Koh TJ, Weiker GG. Effect of an ankle orthosis and ankle ligament anesthesia on ankle joint proprioception. Am J Sports Med. 1994;22(2):223-229.

26. Guskiewicz KM, Perrin DH. Effect of orthotics on postural sway following inversion ankle sprain. J Orthop Sports Phys Ther. 1996;23(5): 326-331.

27. Orteza LC, Vogelbach WD, Denegar CR. The effect of molded and unmolded orthotics on balance and pain while jogging following inversion ankle sprain. J Athl Train. 1992;27(1):80-84.

28. Stude DE, Brink DK. Effects of nine holes of simulated golf and orthotic intervention on balance and proprioception in experienced golfers. J Manipulative Physiol Ther. 1997;20(9):590-601.

29. Anderson DL, Sanderson DJ, Hennig EM. The role of external nonrigid ankle bracing in limiting ankle inversion. Clin J Sport Med. 1995;5(1): $18-24$
30. Thonnard JL, Bragard D, Willems PA, Plaghki L. Stability of the braced ankle. A biomechanical investigation. Am J Sports Med. 1996;24(3): 356-361.

31. Robbins S, Waked E. Factors associated with ankle injuries. Preventive measures. Sports Med. 1998;25(1):63-72.

32. Robbins S, Waked E, McClaran J. Proprioception and stability: foot position awareness as a function of age and footwear. Age Ageing. 1995;24(1):67-72.

33. Robbins S, Waked E, Allard P, McClaran J, Krouglicof N. Foot position awareness in younger and older men: the influence of footwear sole properties. J Am Geriatr Soc. 1997;45(1):61-66.

34. Robbins S, Waked E, Gouw GJ, McClaran J. Athletic footwear affects balance in men. Br J Sports Med. 1994;28(2):117-122.

35. Chiang JH, Wu G. The influence of foam surfaces on biomechanical variables contributing to postural control. Gait Posture. 1997;5: 239-245.

36. Robbins S, Waked E, Krouglicof N. Improving balance. J Am Geriatr Soc. 1998;46(11):1363-1370.
Clinical Interventions in Aging

\section{Publish your work in this journal}

Clinical Interventions in Aging is an international, peer-reviewed journal focusing on evidence-based reports on the value or lack thereof of treatments intended to prevent or delay the onset of maladaptive correlates of aging in human beings. This journal is indexed on PubMed Central, MedLine, the American Chemical Society's 'Chemical Abstracts Ser-

\section{Dovepress}

vice' (CAS), Scopus and the Elsevier Bibliographic databases. The manuscript management system is completely online and includes a very quick and fair peer-review system, which is all easy to use. Visit http://www.dovepress.com/testimonials.php to read real quotes from published authors. 